\title{
Power Quality Considerations in the Planning Phase of Stand-Alone Wind-Powered Micro-Grids
}

\author{
Soheil Mohseni, Alan C. Brent, Daniel Burmester \\ Sustainable Energy Systems, School of Engineering and Computer Science, Victoria University of Wellington, New Zealand
}

\begin{abstract}
This paper proposes a novel multi-objective optimization modelling framework for the optimal design of stand-alone micro-grids (MGs) with high wind power penetration in the presence of nonlinear loads. The key objective of the proposed modelling framework is to facilitate decisionmaking regarding the optimal sizes of the components of windpowered MGs under both the source-end voltage and load current harmonics, which deteriorate the power quality of the system. The problem is formulated as a bi-objective optimization model to minimize the whole-life cost of the system, whilst minimizing the whole system harmonics distortion level, and is solved using the elitist non-dominated sorting genetic algorithm (NSGA-II). The utopia point on Pareto optimal frontier is also determined using a fuzzy decision-making approach. The applicability and effectiveness of the proposed modelling framework are demonstrated on a representative stand-alone wind-powered MG conceptualized for Stewart Island, New Zealand. The simulation results indicate that the proposed model can effectively address the power quality issues in the planning phase of wind-powered sustainable energy systems serving typical nonlinear residential loads.
\end{abstract}

Keywords-Optimal Control; Filters and Filtering; Control Applications

\section{INTRODUCTION}

There has been, and will continue to be, a rapid rise in the use of nonlinear loads, such as personal computers, televisions, refrigerators, printers, electronic ballasts, and so forth, in the residential electric load demand profiles. The high degree of nonlinearity within the electric loads not only results in a harmonically distorted, highly deteriorated power quality, but also reduces the power factor considerably [1], [2]. On the other hand, wind power generation systems, which utilize power electronics devices as an interface to connect to the network, are another source of harmonic contamination (especially the $3^{\text {rd }}, 5^{\text {th }}, 7^{\text {th }}$, and $9^{\text {th }}$ harmonic orders) in the electric power systems of today and modernized smart grids of tomorrow. Hence, establishing appropriate approaches to eliminate the wind generator voltage harmonics is of fundamental importance for a high-quality power supply, especially if the system is mainly reliant on wind power for electricity generation.

Few researchers have addressed the power quality issues in the planning phase of renewable and sustainable energy systems. Abdelsalam and El-Saadany [3] have adopted a probabilistic planning method to reduce the effects of harmonic distortions in a harmonically contaminated distribution system, while optimally determining the types and sizes of both the renewable and non-renewable distributed generation (DG) units to be installed in the system. Hengsritawat et al. [4] have proposed a probabilistic approach to optimally size the photovoltaic (PV) distributed generators to be integrated into a distribution system, while considering the PV panels as a harmonic current source. Pandi et al. [5] have put forward a power quality-constrained single-objective optimization framework aiming at the maximization of the penetration levels of the renewable DG units to be installed in a representative distribution system. Similarly, Kadir et al. [6] have developed a renewable energy penetration maximization model to optimally size and site the PV DG units to be accommodated in a distribution system, whilst adhering to certain harmonic propagation limits.

The shunt active power filter (SAPF) is a mature technology to mitigate the adverse effects of the load current harmonics, whose proper function in power quality enhancement, power factor correction, and voltage regulation is well-documented in the literature [2], [7]. SAPFs are able to eliminate the components of harmonic currents involved in the distorted load current profile through operating as a current source supplying a phase-shifted (by 180 degrees) version of the same harmonic components generated by nonlinear loads, whilst also having the capability to improve the load power factor, if accompanied by a proper control strategy [8].

Nonetheless, accommodating a high penetration of wind power in an electric power system undermines the accuracy of SAPFs due to their distorted, unbalanced, asymmetric voltage profiles. Therefore, most of the prominent control strategies for SAPFs, such as the constant instantaneous source power control, the sinusoidal current control, and the generalized Fryze current control, whose performances are compared with each other in terms of addressing optimal harmonic suppression targets in [9], would be inefficient for the applications of power systems dominated by wind resources for electricity generation. In order to overcome the inefficacy of basic SAPFs in wind power integrated systems, Rahmani and Tavakoli Bina [10] have proposed an advanced universal power quality conditioning system (AUPQS), which is constructed by integrating a SAPF, a series active power filter, and an active rectifier. Through conducting numeric simulations, it has been demonstrated in [10] that the use of a series active power filter, substantially cancels out the negative effects of the wind generator's asymmetric, distorted voltage profile on the SAPF's efficiency. The authors have also put forward an advanced generalized theory of instantaneous power (A-GTIP), to optimally control their devised AUPQS. Owing to the unique properties of the AUPQS and the A-GTIP control theory in mitigating the negative effects of load current and wind turbine (WT) voltage harmonics, they are adopted in this study for the compensation of load current harmonics (i.e. induced by nonlinear capacitive and/or inductive loads) under non-ideal conditions of voltage waveforms (voltage sags/swells) produced by a wind generator incorporated in a stand-alone micro-grid (MG). 
However, SAPFs are still relatively expensive [11], especially if they are complemented with series active power filters and active rectifiers to improve their efficiency for wind-powered systems' applications. Hence, developing a power quality-infused optimal planning framework is necessary to assist renewable and sustainable energy system designers in making appropriate decisions regarding the optimum capacities of SAPFs, taking into account the tradeoff between the project's life-cycle cost and the desirable level of power quality.

The above review of the literature indicates a lack of a systematic study to evaluate the cost-efficiency of addressing the power quality issues in the design phase of electric power systems dominated by renewable energy sources, especially for off-grid applications. Thus, this study proposes a multiobjective optimization framework for the optimal planning of off-grid wind-powered MGs feeding unbalanced nonlinear loads, while considering the whole-life cost minimization and power quality maximization as two separate, conflicting objectives of the optimization problem.

The remainder of this paper is organized as follows. Section II briefly introduces the non-dominated sorting genetic algorithm II (NSGA-II), employed in this study as the multi-objective optimization algorithm. Section III describes the structure of the wind-powered MG network, used as a testcase system to evaluate the performance of the proposed method. The proposed power quality/life-cycle cost-based optimal planning modelling framework for wind-powered MGs is developed in Section IV. The results of the case study carried out to examine the effectiveness of the proposed multiobjective optimal investment planning method are presented and discussed in Section V. Finally, Section VI concludes the paper and summarizes the key findings.

\section{A BRIEF OVERVIEW OF THE NSGA-II}

The NSGA-II, which is a multi-objective evolutionary optimization algorithm, is used in this study for the multiobjective decision-making, involving trade-offs between conflicting goals of life-cycle cost minimization and power quality maximization. The pseudo-code of the NSGA-II is shown in Algorithm 1. The NSGA-II is built on the NSGA by: (i) alleviating its computational complexity, (ii) adding an elitism feature to it, and (iii) specifying a sharing parameter that ensures the diversity in the population [12]. The number of chromosomes (search agents) and the maximum number of iterations equal to 40 and 200, respectively. The reader is referred to [12] for a more detailed explanation of the NSGAII and on how to optimally set its parameters.

\begin{tabular}{l}
\hline Algorithm 1 Pseudo-code of the NSGA-II \\
\hline Initialize the population of chromosomes \\
$n$ : size of the non-dominated solutions in the solution set $S$ \\
$m$ : number of the objectives \\
$C D[i]$ : the crowding distance of the $i$-th chromosome \\
$f[i, j]:$ the $j$-th objective value returned by the $i$-th individual \\
for $i=1$ to $n$ do \\
$C D[i]=0$ \\
end for \\
for $j=1$ to $m$ do \\
Sort the solution set of the $j$-th objective in ascending order \\
$C D[1]=C D[n]=$ inf
\end{tabular}

$$
\begin{aligned}
& \text { for } i=2 \text { to } n-1 \text { do } \\
& \quad C D[i]=C D[i]+(f[i+1, j]-f[i-1, j]) /(\max (f[*, j]) \\
& \quad-\min (f[*, j])) \\
& \text { end for } \\
& \text { end for } \\
& \text { while Iter }<\text { Max_Iter do }
\end{aligned}
$$

Obtain the offspring population from the tournament selection, crossover, and mutation procedures

Rank the search agents by non-dominated sorting and crowding distance concepts

Select the best search individuals from the parents and offspring

end while

return Pareto optimal solution set

\section{DESCRIPTION OF THE MG SYSTEM UNDER STUDY}

In order to verify the effectiveness of the proposed biobjective decision-making model, an AC-coupled MG test system is conceptualized. The MG system, whose schematic diagram and power flow are shown in Fig. 1, integrates a WT generation system; a hybrid energy storage system, consisting of a hydrogen $\left(\mathrm{H}_{2}\right)$ sub-system and a supercapacitor (SC) bank; and some power converters.

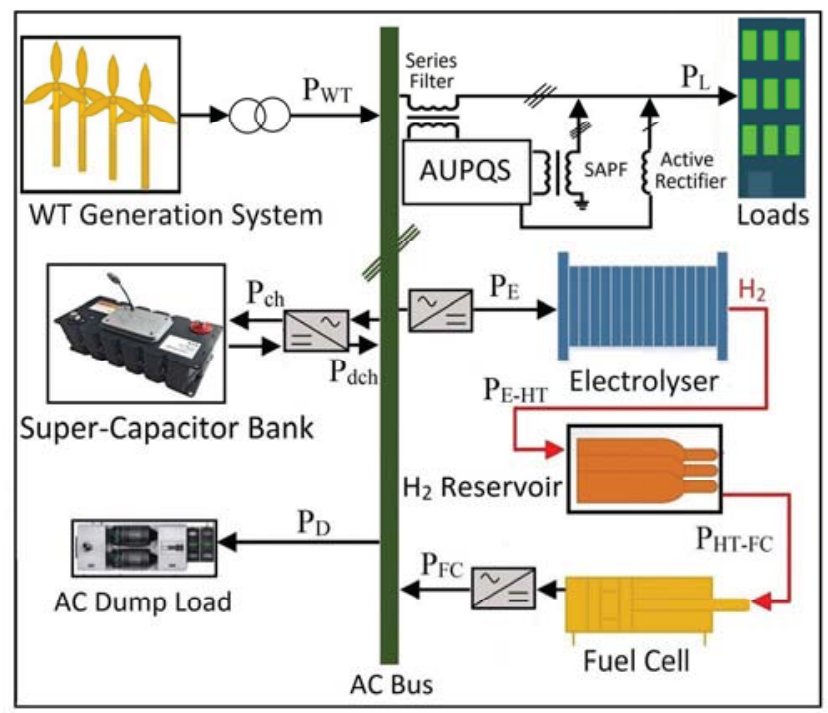

Fig. 1. A typical stand-alone wind-powered MG system.

\section{A. Mathematical Modelling of the System Components}

1) WT generation system: The Fuhrländer FL100 WT, whose power curve is shown in Fig. 2, is considered as the sole primary power source in this scheme [13]. The costs associated with the transformer connecting the WTs to the MG's network are taken into account in the costs associated with the WT power plant.

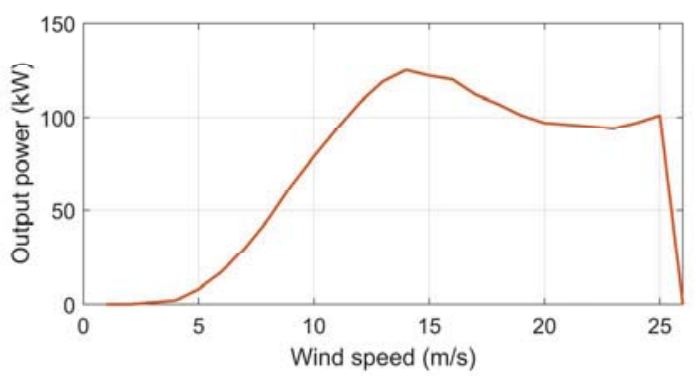

Fig. 2. Power curve of the Fuhrländer FL100 WT. 
2) Hybrid energy storage system: The hybrid energy storage system incorporated in the devised $\mathrm{MG}$ system, comprises of an $\mathrm{H}_{2}$ sub-system and an SC bank to back up the system in the face of intermittent loads and/or wind power supply. Also, owing to the use of SCs (that offer high power density) in the architecture of the hybrid energy storage system, the dynamic stability of the conceptualized system is ensured.

a) Hydrogen sub-system: $\mathrm{The} \mathrm{H}_{2}$ sub-system acts as an inter-hour supply-demand balancing system, which absorbs the excess power by water electrolysis - a process through which electricity is utilized to dissociate water into hydrogen and oxygen. The produced hydrogen is then stored in an $\mathrm{H}_{2}$ reservoir, which could be used in a polymer electrolyte membrane (PEM) fuel cell backing up the MG network against the inter-hour volatility in the forecasted load power and/or the output power from the WT generation system.

The hydrogen power delivered from the PEM electrolyser to the $\mathrm{H}_{2}$ reservoir at time step $t$ is calculated by:

$$
P_{E-H T}(t)=P_{E}(t) \times \eta_{E}
$$

where $P_{E}(t)$ represents the wind electricity consumption of the electrolyser, during time step $t$, to produce hydrogen and $\eta_{E}$ denotes the electrolyser's efficiency, which is equal to $60 \%$ in this study.

The energy content of the $\mathrm{H}_{2}$ reservoir at the $t$-th time step, which is constrained to lie between the minimum and maximum allowable energy levels, can then be calculated by:

$$
E_{H T}(t)=E_{H T}(t-1)+\left(P_{E-H T}(t)-\frac{P_{H T-F C}(t)}{\eta_{H T}}\right) \times \Delta t
$$

where $P_{H T-F C}(t)$ represents the hydrogen power delivered from the tank to the fuel cell at the $t$-th time step, $\eta_{H T}$ is the $\mathrm{H}_{2}$ reservoir's round-trip efficiency (i.e. $95 \%$ ), and $\Delta t$ is the time slot increment, i.e. $1 \mathrm{~h}$ [14].

The equation in (3) can be used at every time step to calculate the mass of hydrogen reserved in the tank.

$$
m_{H T}(t)=\frac{E_{H T}(t)}{H H V_{H_{2}}},
$$

where $\mathrm{HHV}_{\mathrm{H}_{2}}$ represents the higher heating value of hydrogen, which is equal to $39.7 \mathrm{kWh} / \mathrm{kg}$ [15].

Ultimately, the stored $\mathrm{H}_{2}$ in the tank is converted into electricity by a PEM fuel cell as:

$$
P_{F C}(t)=P_{H T-F C}(t) \times \eta_{F C}
$$

where $\eta_{F C}$ represents the PEM fuel cell's efficiency, which is equal to $40 \%$ in this study [16].

b) Super-capacitor bank: The SC bank, which consists of MAXWELL EDLC (3.23 Wh) SC modules, serves the transient power required by the residential loads, and thereby improves the dynamic stability of the system. That is, the SC bank acts as a buffer to smooth out transient fluctuations in the power balance equation of the $\mathrm{MG}$ system [17].

Likewise to the $\mathrm{H}_{2}$ reservoir, the energy content of the SC bank at time step $t$, which is constrained to lie within a predefined allowable range, can be determined by:

$$
E_{S C}(t)=E_{S C}(t-1)+\left(P_{c h}(t)-\frac{P_{d c h}(t)}{\eta_{S C}}\right) \times \Delta t,
$$

where $P_{c h}(t)$ and $P_{d c h}(t)$ are the charging and discharging powers of the SC bank at the $t$-th time step, respectively; and $\eta_{S C}$ is the round-trip efficiency of the SC bank, i.e. 95\%.

3) Power converters: The utilized power converters within the configuration of the system include DC/AC inverters, $\mathrm{AC} / \mathrm{DC}$ rectifiers, and bidirectional $\mathrm{AC} / \mathrm{DC}-$ $\mathrm{DC} / \mathrm{AC}$ converters, through which the MG components are coupled to a common $3 \Phi \mathrm{AC}$ bus, which has a line-line voltage of $440 \mathrm{~V}$. The structures and characteristics of the above-mentioned converters, which are modelled by their efficiencies, are described in [18]. In this analysis, the costs and efficiencies of these converters are incorporated in their corresponding components.

4) $A U P Q S$ : As mentioned earlier, the AUPQS proposed by Rahmani and Tavakoli Bina [10] is adopted in this study to compensate for the harmonics generated by nonlinear loads, as well as for the source-end voltage harmonics. The AUPQS is composed of a SAPF, which takes the responsibility to eliminate the harmonic components introduced by nonlinear loads; a series active power filter, which mitigates the negative effects of the WT power plant's asymmetric, unbalanced distorted voltage profile on the SAPF's efficiency; and a single-phase active rectifier, which regulates the DC-link voltage of the SAPF without generating any further harmonic distortions.

\section{B. Power Quality Characterization}

In order to carry out the power quality analysis in the planning phase of an MG, both the load current and sourceend voltage harmonics could be reflected in the hourly average energy scheduling strategy, assuming that the power quality parameters are measured at hourly intervals over the considered operational time period. Also, for the sake of simplicity, it is assumed that the order and magnitude of the considered load current and source voltage harmonics do not change when reflected in the corresponding powers by using the famous equation $P=V_{r m s} I_{r m s} \cos \theta$, where $V_{r m s}$ is the rms value of voltage, $I_{r m s}$ is the rms value of current, and $\cos \theta$ is the power factor. As mentioned earlier, in this analysis, the deterioration of power quality could be stemming from the nonlinearity of loads and the harmonic emissions of the WT power plant.

1) Wind power generation system: Fig. 3 characterizes the percentage of the total harmonic distortion (THD) of the injected power by a $100 \mathrm{~kW}$ WT at various wind speed levels with the system frequency around $50 \mathrm{~Hz}$ [19]. The THD in this analysis contains harmonics up to the $33^{\text {rd }}$ order. As shown in Fig. 3, the value of the THD is very high at low wind speeds. By comparing Figs. 3 and 4, it can be deduced that the THD is nearly proportional to the reciprocal of the WT's output power.

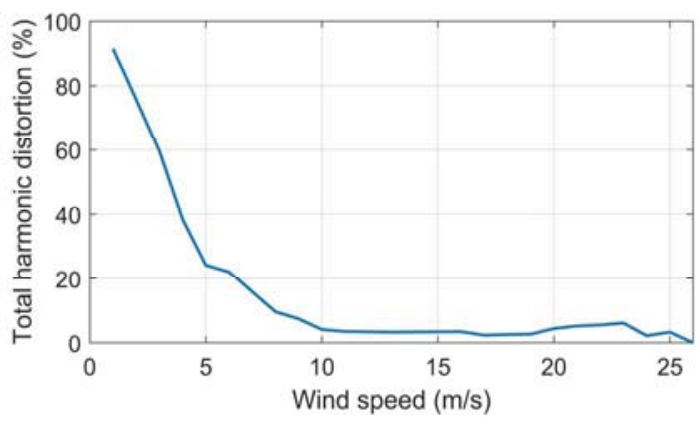

Fig. 3. THD characterization of a $100 \mathrm{~kW}$ WT at various wind speeds. 
2) Residential electrical loads: The THD of the load power under the peak load conditions is set to $32 \%$ based on the investigations conducted in [20] on a typical residential electric load pattern. Each time step in the load power profile is then assigned a THD index by proportionally scaling down the value of THD defined for the peak load conditions.

\section{Operational Strategy of the System}

The MG network is operated following a cycle-charging operational strategy [21]. Accordingly, the excess wind power is used to fill the $\mathrm{H}_{2}$ reservoir and charge the $\mathrm{SC}$ modules, while the shortage of the wind power generation capacity is compensated for by operating the fuel cell and discharging of SCs. Accordingly, the power imbalance signal between the available power supply and the consumer demand at each time step is initially decomposed into the low- and high-frequency components by the use of a low-pass energy filter, whose transfer function is expressed by (6). Our steps proceed in the same way as indicated in [22] for the operation of a hybrid energy storage system consisting of the battery and SC banks - with the aim of optimally sizing the hybrid system.

$$
H(s)=\frac{K \omega_{0}^{2}}{s^{2}+\left(\omega_{0} / Q\right) s+\omega_{0}^{2}},
$$

where $\omega_{0}$ represents the cut-off frequency, $K$ is the DC gain, and $Q$ denotes the quality, which is equal to $(1 / 2 \xi)$, where $\xi$ is the damping factor.

Then, the SC bank absorbs/injects the high-frequency component of the excess of wind power supply/the shortfall in the required power demand; while the $\mathrm{H}_{2}$ sub-system uses the low-frequency component of the excess power to produce hydrogen and supplies the low-frequency component of the power shortage by operating the fuel cell.

When the SC bank, the $\mathrm{H}_{2}$ reservoir, or the fuel cell is not able to afford the requested power, a power outage occurs, which reduces the system's reliability. On the other hand, any surplus wind power beyond the capacity of the SC bank, $\mathrm{H}_{2}$ tank, or the electrolyser, is dumped through an AC dump load, whose life-cycle costs are assumed to be negligible.

The A-GTIP theory is employed to control the AUPQS apparatus, as suggested by Rahmani and Tavakoli Bina [10]. Accordingly, the transfer function, $G(j \omega)$, defined in (7) is utilized to relate the load current, $I_{L}$, to the AUPQS's SAPF current. The reader is referred to [10] for details on how to derive this transfer function based on the A-GTIP theory.

$$
\left\{\begin{array}{l}
I_{L}(j \omega)=\frac{V_{S}(j \omega)-V_{V R}(j \omega)}{Z_{L}(j \omega)+(1-G(j \omega)) Z_{S}(j \omega)}, \\
I_{S}(j \omega)=I_{L}(j \omega)(1-G(j \omega)),
\end{array}\right.
$$

where $V_{S}$ and $I_{S}$ respectively represent the source-end voltage and current, $Z_{S}$ is the source-end impedance, $Z_{L}$ is the load impedance, and $V_{V R}$ is the AUPQS voltage, regulated by its voltage regulator element.

\section{Proposed Bi-ObJective Optimization Model}

\section{A. Objective Functions}

The minimization of the life-cycle cost of the conceptualized $\mathrm{MG}$ and the maximization of the power quality of the system are considered as two conflicting objectives in this study.
1) Objective function 1: The life-cycle cost of the MG is modelled using the net present cost (NPC) concept. The total NPC (TNPC) of the MG, which must be minimized, is the sum of all the NPCs of the MG's components, as follows:

$$
\begin{aligned}
T N P C= & N P C_{W T}+N P C_{E}+N P C_{R}+N P C_{F C}+N P C_{S C} \\
& +N P C_{A S},
\end{aligned}
$$

where $N P C_{W T}, N P C_{E}, N P C_{R}, N P C_{F C}, N P C_{S C}$, and $N P C_{A S}$ respectively represent the NPCs of the WT power plant, electrolyser, $\mathrm{H}_{2}$ reservoir, fuel cell, $\mathrm{SC}$ bank, and the AUPQS apparatus.

The NPC of each component is determined by [23]:

$$
N P C=N \times\left(C C+R C \times K+\frac{O \& M}{C R F(d, R)}-S V\right),
$$

where $N, C C, R C, O \& M$, and $S V$ respectively represent the optimal size, capital cost, replacement cost, operation and maintenance cost, and salvage value of the component; $K$ and $C R F$ respectively stand for the single payment present worth and capital recovery factor; $d$ is the real interest rate per annum (i.e. $6 \%$ ); and $R$ is the project's life span (i.e. 20 years) [24].

2) Objective function 2: Since the harmonic emissions are originated from two different nodes in the considered MG's topology (i.e. load and wind generator nodes), motivated by the idea proposed by Liu et al. [25], the whole system harmonics distortion level (WSHDL) is considered in this analysis as the index for power quality. The WSHDL of an electric power system can be calculated by:

$$
W S H D L=\sqrt{\frac{\sum_{i=1}^{n} T H D_{i}}{n}},
$$

where $n$ denotes the number of nodes that are associated with power quality issues, which is equal to 2 in this case, as illustrated above.

In order to measure the power quality of the system at the planning stage, the WSHDL index can be adapted for application in the design studies of MGs considering power quality aspects as:

$$
W S H D L_{\text {planning }}=\frac{\sum_{j=1}^{m} W S H D L_{j}}{m},
$$

where $m$ represents the considered operational timeframe, i.e. 8760 hours in this analysis. The minimization of the $W S H D L_{\text {planning }}$ index corresponds to the maximization of the power quality, which is the second objective of the optimization problem.

Finally, a posteriori method based on the fuzzy set theory could be adopted to extract the best compromise solution among non-dominated solutions, as explained step-by-step in [26].

\section{B. Constraints}

In order to evaluate the reliability of electricity supply in the conceptualized MG scheme, the loss of power supply probability (LPSP) index is employed in this study, which can be determined by (12) [27].

$$
L P S P=100 \times \frac{\left.\sum_{i=1}^{N} \operatorname{hours}\left[P_{\text {supp }}(i)<P_{\text {dem }}(i)\right)\right]}{N},
$$


where $P_{\text {supp }}$ represents the supplied electric power, $P_{\text {dem }}$ denotes the demand for electricity, and $N$ is the total number of hours considered in the operational time scale, i.e. 8760 . The desired value for the LPSP is set at zero percent in this study. In addition, the optimization problem is subject to the constraints on the: (1) equality of the initial and final energy reserves, (2) supply-demand power balance at each time slot of the MG operation, and (3) keeping of the energy levels of the $\mathrm{SCs}$ and $\mathrm{H}_{2}$ tank within their predefined allowable limits.

\section{SimUlation Results AND Discussion}

The proposed bi-objective modelling framework was simulated using the MATLAB software. In this regard, the nonlinearity of residential loads, the contamination of the output power of the WT generation system with harmonics, and the harmonic elimination function of the AUPQS apparatus are simulated using appropriate functions defined with Simulink blocks. Also, the built-in THD block in Simulink is used to measure the THDs of source-end voltage and load current signals. The partial waveforms (in the order of 0 to $0.1 \mathrm{~s}$ ) of the load current and source-end voltage are considered as representatives of their hourly averaged values.

\section{A. Input Data}

The conceptualized MG model is considered to provide clean, reliable electricity to a remote community residing on Stewart Island, New Zealand (latitude $46.9973^{\circ} \mathrm{S}$, longitude $167.8372^{\circ} \mathrm{E}$ ), with a population of around 400 people. The load power profile for Stewart Island is forecasted based on the New Zealand GREEN Grid household electricity demand study [28] and is polluted with harmonics in accordance with the harmonic levels reported in [20] for a typical residential electric load pattern. The simulation is conducted on an 8760$\mathrm{h}$ operational time scale with hourly-basis, year-round climatic and load data streams. However, for the sake of better visualization, the monthly mean 24 -h profile for the forecasted electric load power is shown in Fig. 4.

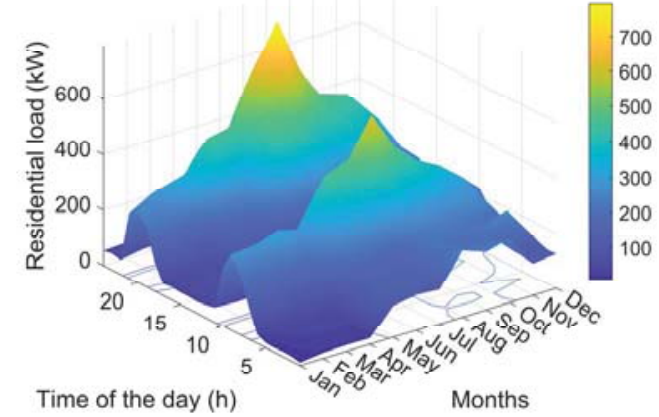

Fig. 4. Forecasted monthly mean daily electrical load power profile.

The wind speed profile is forecasted by averaging the 10 years (2009-2018) wind speed data collected for the case study site at intervals of 1-h [29], whose monthly mean daily profile is shown in the form of a heat map-like plot in Fig. 5.

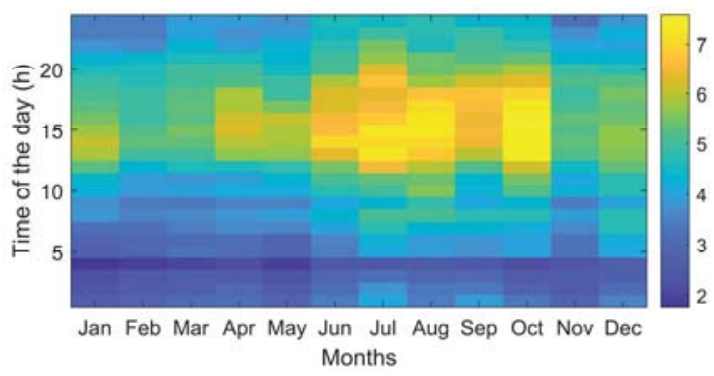

Fig. 5. Forecasted wind speed profile for Stewart Island $(\mathrm{m} / \mathrm{s})$
Moreover, the techno-economic specifications of the MG components are presented in Table I [17], [22], [30], [31]. The costs reported for the AUPQS are estimated based on the costs of the state-of-the-art SAPFs, series active power filters, and active rectifiers, whilst considering the costs related to its control circuit. All costs are reported in U.S. dollars.

TABLE I. TECHNO-ECONOMIC SPECIFICATIONS OF THE MG COMPONENTS

\begin{tabular}{ccccc}
\hline Component & $C C$ & $R C$ & O\&M & $\begin{array}{c}\text { Lifetime } \\
\text { (years) }\end{array}$ \\
\hline WT & $\$ 120 \mathrm{k} / \mathrm{unit}$ & $\$ 100 \mathrm{k} / \mathrm{unit}$ & $\$ 4.6 \mathrm{k} / \mathrm{unit} /$ year & 20 \\
Electrolyser & $\$ 1 \mathrm{k} / \mathrm{kW}$ & $\$ 1 \mathrm{k} / \mathrm{kW}$ & $\$ 20 / \mathrm{kW} /$ year & 15 \\
$\mathrm{H}_{2}$ reservoir & $\$ 470 / \mathrm{kg}$ & $\$ 470 / \mathrm{kg}$ & $\$ 9 / \mathrm{kg} /$ year & 20 \\
Fuel cell & $\$ 1.1 \mathrm{k} / \mathrm{kW}$ & $\$ 0.9 \mathrm{k} / \mathrm{kW}$ & $\$ 28 / \mathrm{kW} /$ year & 5 \\
SC & $\$ 32 / \mathrm{unit}$ & $\$ 32 / \mathrm{unit}$ & $\$ 0.5 / \mathrm{unit} /$ year & 10 \\
AUPQS & $\$ 2.8 \mathrm{k} / \mathrm{kVA}$ & $\$ 2.6 \mathrm{k} / \mathrm{kVA}$ & $\$ 52 / \mathrm{kVA} /$ year & 20 \\
\hline
\end{tabular}

\section{B. Bi-Objective Design Results}

Pareto optimal frontier of the obtained non-dominated solutions, by solving the formulated problem using the NSGA-II subject to the constraints imposed on the operation and design of the considered test-case MG system is shown in Fig. 6. The TNPC of the MG for the case, where no harmonic suppression mechanism is conducted ( $W S H D L=19.23 \%$ ), is found to be $\$ 6,091,274$. On the contrary, as can be seen in Fig. 6, the TNPC of the MG rises to $\$ 8,571,399$ when the harmonic emissions are completely eradicated $(W S H D L=0 \%)$.

As shown in Fig. 6, the best compromise solution obtained by the fuzzy decision-making approach from the set of Pareto optimal solutions, when an additional constraint of $W S H D L_{\max }<5 \%$, as suggested by Liu et al. [25], is added to the optimization protocol, is found to be $(1.96 \%$, $\$ 8,195,337)$. These results collectively indicate that establishing appropriate mechanisms to cope with the power quality issues arising from the extensive use of nonlinear loads and the deployment of wind power is of paramount importance towards reflecting the real-world conditions in a more precise way in the long-term investment planning phase of stand-alone wind-powered energy systems to thereby avoid future problems.

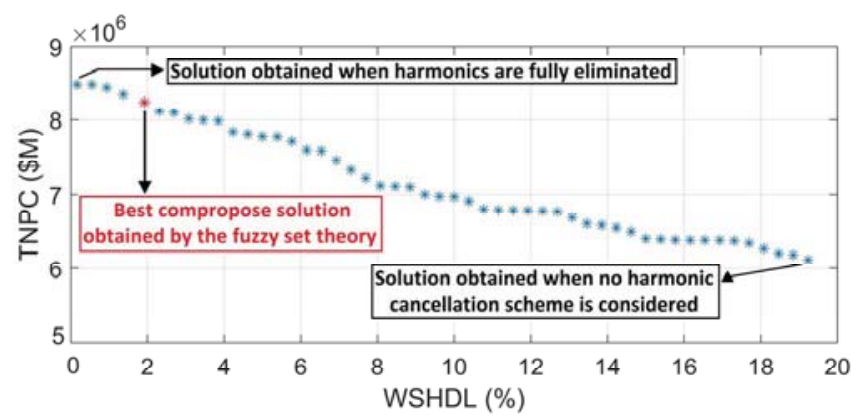

Fig. 6. Pareto optimal solution set obtained by the NSGA-II.

In order to offer a better understanding of how the TNPC of the conceptualized $\mathrm{MG}$ can be divided among its constituent components, Table II details the optimum equipment sizes obtained at the best compromise solution point on Pareto optimal frontier.

TABLE II. OPTIMAL EQUiPMENT SizES OF THE MG AT THE UTOPIA POINT

\begin{tabular}{cccccc}
\hline $\begin{array}{c}\text { WT } \\
(\text { no. })\end{array}$ & $\begin{array}{c}\mathrm{SC} \\
(\text { no. })\end{array}$ & $\begin{array}{c}\text { Electrolyser } \\
(\mathrm{kW})\end{array}$ & $\begin{array}{c}\mathrm{H}_{2} \\
\text { reservoir } \\
(\mathrm{kg})\end{array}$ & $\begin{array}{c}\text { Fuel } \\
\text { cell } \\
(\mathrm{kW})\end{array}$ & $\begin{array}{c}\text { AUPQS } \\
(\mathrm{kVA})\end{array}$ \\
\hline 26 & 9,415 & 1,391 & 853 & 320 & 621 \\
\hline
\end{tabular}


Furthermore, the impact of using the AUPQS apparatus which has successfully mitigated the harmonics emissions of nonlinear loads and the WT generator - on the power factor is analyzed. Accordingly, the average power factor over the operational time frame is calculated for two cases, with and without a harmonic compensation scheme. The results obtained at the utopia point on Pareto optimal frontier are used for the case with harmonic elimination. Based on the numerical results, the power factor improves from 0.810 to 0.994 by integrating the AUPQS into the proposed MG.

\section{CONCLUSIONS}

This paper has proposed a bi-objective decision-making modelling framework involving trade-offs between the whole-life cost and power quality of a conceptualized windpowered MG feeding nonlinear loads to be installed on Stewart Island, New Zealand. The AUPQS apparatus, which integrates a SAPF, a series active power filter, and an active rectifier, is utilized to compensate for harmonics generated by nonlinear loads and the WT power plant, which is controlled using the A-GTIP theory. The bi-objective optimization problem of minimizing the life-cycle cost of the MG (i.e. affected by its optimum equipment capacity), whilst maximizing its power quality, is solved using the NSGA-II and Pareto optimal frontier of the solutions is achieved. The best compromise solution point on Pareto frontier is further determined utilizing the fuzzy set theory. The findings of this study support the idea that devising appropriate power quality improvement schemes in the planning phase of renewable energy systems is of prime importance for a more realistic assessment of their costs and consequences.

\section{REFERENCES}

[1] W. U. Tareen, S. Mekhilef, M. Seyedmahmoudian, and B. Horan, "Active power filter (APF) for mitigation of power quality issues in grid integration of wind and photovoltaic energy conversion system," Renew. Sustain. Energy Rev., vol. 70, pp. 635-655, 2017.

[2] Y. Naderi et al., "An overview of power quality enhancement techniques applied to distributed generation in electrical distribution networks," Renew. Sustain. Energy Rev., vol. 93, pp. 201-214, 2018.

[3] A. A. Abdelsalam and E. F. El-Saadany, "Probabilistic approach for optimal planning of distributed generators with controlling harmonic distortions," IET Gener. Transm. Distrib., vol. 7, pp. 1105-1115, 2013.

[4] V. Hengsritawat, T. Tayjasanant, and N. Nimpitiwan, "Optimal sizing of photovoltaic distributed generators in a distribution system with consideration of solar radiation and harmonic distortion," Int. J. Electr. Power Energy Syst., vol. 39, no. 1, pp. 36-47, 2012.

[5] V. R. Pandi, H. H. Zeineldin, and W. Xiao, "Determining optimal location and size of distributed generation resources considering harmonic and protection coordination limits," IEEE Trans. Power Syst., vol. 28, no. 2, pp. 1245-1254, 2013.

[6] A. F. A. Kadir, T. Khatib, and W. Elmenreich, "Integrating photovoltaic systems in power system: Power quality impacts and optimal planning challenges," Int. J. Photoenergy, p. 7, 2014.

[7] P. Kanjiya, V. Khadkikar, and H. H. Zeineldin, "Optimal control of shunt active power filter to meet IEEE Std. 519 current harmonic constraints under nonideal supply condition," IEEE Trans. Ind. Electron., vol. 62, no. 2, pp. 724-734, 2015.

[8] L. Morán, J. Dixon, and M. Torres, "41 - active power filters," in Power electronics handbook, $4^{\text {th }}$ ed., M. H. Rashid, Ed. ButterworthHeinemann, 2018, pp. 1341-1379.

[9] M. Cirrincione, M. Pucci, G. Vitale, and A. Miraoui, "Current harmonic compensation by a single-phase shunt active power filter controlled by adaptive neural filtering," IEEE Trans. Ind. Electron., vol. 56, no. 8, pp. 3128-3143, 2009.

[10] B. Rahmani and M. Tavakoli Bina, "Reciprocal effects of the distorted wind turbine source and the shunt active power filter: full compensation of unbalance and harmonics under 'capacitive non-linear load' condition," IET Power Electron., vol. 6, no. 8, pp. 1668-1682, 2013.
[11] S. Deilami, M. A. S. Masoum, and M. Moghbel, "Derating active power filters considering network and bus voltage total harmonic distortions," in Proc. $16^{\text {th }}$ Int. Conf. Environ. Electr. Eng., Florence, Italy, 7-10 June 2016, pp. 1-5.

[12] K. Deb, A. Pratap, S. Agarwal, and T. Meyarivan, "A fast and elitist multiobjective genetic algorithm: NSGA-II," IEEE Trans. Evol. Comput., vol. 6, no. 2, pp. 182-197, 2002.

[13] C. Li et al., "Evaluation of wind energy resource and wind turbine characteristics at two locations in China," Technol. Soc., vol. 47, pp. 121-128, 2016.

[14] S. M. Moghaddas-Tafreshi, S. Mohseni, M. E. Karami, and S. Kelly, "Optimal energy management of a grid-connected multiple energy carrier micro-grid," Appl. Therm. Eng., vol. 152, pp. 796-806, 2019.

[15] S. Mohseni and S. M. Moghaddas-Tafreshi, "A multi-agent system for optimal sizing of a cooperative self-sustainable multi-carrier microgrid," Sustain. Cities Soc., vol. 38, pp. 452-465, 2018.

[16] S. Mohseni, A. C. Brent, and D. Burmester, "A Reliability-Oriented Cost Optimisation Method for Capacity Planning of a Multi-Carrier Micro-Grid: A Case Study of Stewart Island, New Zealand," arXiv preprint, arXiv:1906.09544, 2019.

[17] S. Mohseni, A. C. Brent, and D. Burmester, "A Sustainable Energy Investment Planning Model Based on the Micro-Grid Concept Using Recent Metaheuristic Optimization Algorithms," in Proc. 2019 IEEE Cong. Evol. Comput., Wellington, New Zealand, 10-13 Jun. 2019, pp. 219-226.

[18] M. Farhadi and M. Abapour, "Three-Switch Three-Phase Inverter with Improved DC Voltage Utilization," IEEE Trans. Ind. Electron., vol. 66, no. 1, pp. 14-24, 2019.

[19] V. Preciado, M. Madrigal, E. Muljadi, and V. Gevorgian, "Harmonics in a wind power plant," in Proc. 2015 IEEE Power Energy Soc. Gen. Meet., Denver, CO, USA, 26-30 Jul. 2015, pp. 1-5.

[20] J. Niitsoo, J. Kilter, I. Palu, P. Taklaja, and L. Kütt, "Harmonic levels of domestic and electrical vehicle loads in residential distribution networks," in Proc. 2013 IEEE AFRICON Conf., Pointe-Aux-Piments, Mauritius, 9-12 Sept. 2013, pp. 1-5.

[21] S. Mohseni, A. C. Brent, D. Burmester, and A. Chatterjee, "Optimal Sizing of an Islanded Micro-Grid Using Meta-Heuristic Optimization Algorithms Considering Demand-Side Management," in Proc. Australas. Univ. Power Eng. Conf., Auckland, New Zealand, 27-30 Nov. 2018, pp. 1-6.

[22] U. Akram, M. Khalid, and S. Shafiq, "An innovative hybrid wind-solar and battery-supercapacitor microgrid system-development and optimization," IEEE Access, vol. 5, pp. 25897-25912, 2017.

[23] S. Mohseni and S. M. Moghaddas-Tafreshi, "Development of a multiagent system for optimal sizing of a commercial complex microgrid," arXiv preprint, arXiv:1811.12553, 2018.

[24] S. Mohseni, A. C. Brent, and D. Burmester, "A demand responsecentred approach to the long-term equipment capacity planning of gridindependent micro-grids optimized by the moth-flame optimization algorithm," Energy Convers. Manag., vol. 200, p. 112105, 2019.

[25] Z. Liu, X. Xu, and E. Makram, "Harmonics assessment and mitigation: A case study on an unbalanced stand-Alone microgrid integrated with PV," in Proc. 2015 North Am. Power Symp., Charlotte, NC, USA, 4-6 Oct. 2015 pp. 1-6.

[26] A. A. A. Mohamed, A. A. M. El-Gaafary, Y. S. Mohamed, and A. M. Hemeida, "Multi-objective states of matter search algorithm for TCSCbased smart controller design," Electr. Power Syst. Res., vol. 140, pp. 874-885, 2016.

[27] E. Ofry and A. Braunstein, "The Loss of Power Supply Probability as a Technique for Designing Stand-Alone Solar Electrical (Photovoltaic) Systems," IEEE Power Eng. Rev., vol. PER-3, no. 5, pp. 34-35, 1983.

[28] B. Anderson et al., New Zealand GREEN Grid household electricity demand study 2014-2018. [Data Collection].

[29] CliFlo: NIWA's National Climate Database on the Web, [Data Collection]. Available: http://cliflo.niwa.co.nz/, Retrieved Dec. 2018.

[30] S. M. Moghaddas-Tafreshi, M. Jafari, S. Mohseni, and S. Kelly, "Optimal operation of an energy hub considering the uncertainty associated with the power consumption of plug-in hybrid electric vehicles using information gap decision theory," Int. J. Electr. Power Energy Syst., vol. 112, pp. 92-108, 2019.

[31] S. Mohseni and S. M. Moghaddas-Tafreshi, "A multi-agent approach to optimal sizing of a combined heating and power microgrid," arXiv preprint, arXiv:1812.11076, 2018. 